\title{
Gold-Catalyzed Hydrophenoxylation of Propargylic alcohols and amines: Synthesis of Phenyl Enol Ethers
}

\author{
Victor Laserna, Catherine Jeapes Rojas and Tom D. Sheppard*
}

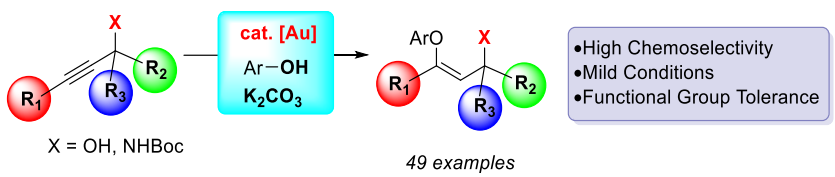

\begin{abstract}
A practical method for the synthesis of phenyl enol ethers is reported. The combination of a gold(I) catalyst and potassium carbonate selectively mediates the addition of phenols to propargylic alcohols/amines in a chemo-, regio- and stereoselective fashion in high yield. The resulting enol ethers are formed exclusively with a Z-configuration and can be obtained from a wide array of phenols and propargylic alcohols or amines with the reaction showing excellent functional group tolerance.
\end{abstract}

The discovery of new synthetic methods for the formation of $\mathrm{C}-\mathrm{O}$ bonds has drawn considerable attention in synthetic organic chemistry. ${ }^{1-4}$ A straightforward approach consists of the addition of alcohols to unsaturated bonds, particularly alkynes, ${ }^{5,6}$ in an intramolecular ${ }^{7-10}$ or intermolecular ${ }^{11-14}$ fashion. Compared to the well-developed hydroamination of alkynes, ${ }^{15}$ hydroalkoxylation reactions are far less developed, probably due to the lower nucleophilicity of alcohols compared to amines. The addition of alcohols to alkynes yields enol ethers, although acetal products have also been observed ${ }^{16}$ as double addition of the alcohol is possible. These additions usually have a high activation barrier which is overcome by the use of harsh conditions or through metal catalysis. Many methods have been reported over the years with a wide array of metal catalysts including $\mathrm{Cu},{ }^{17} \mathrm{Rh},{ }^{18} \mathrm{Ru},{ }^{19} \mathrm{Ir}_{,}{ }^{20} \mathrm{Pt}^{21}$ or $\mathrm{Au} .{ }^{22}$

Over the past decade Au catalysis has become considered as the most effective approach to achieve hydration, ${ }^{23}$ hydroamination $^{15}$ or hydroalkoxylation ${ }^{6}$ of alkynes efficiently with a wide range of substrates. Gold-catalyzed intramolecular hydroalkoxylation of alkynes has proved to be a very useful method for the synthesis of various heterocycles ${ }^{24-26}$ and natural products, ${ }^{27}$ and although more challenging, the intermolecular version of this reaction has been described for primary ${ }^{13}$ and secondary ${ }^{22}$ alcohols and to a lesser extent, with phenols. ${ }^{28-30}$ In these reactions, internal alkynes usually show considerably lower reactivity in comparison to terminal alkynes, ${ }^{6}$ but the nature of the alcohol species has a more significant impact on the feasibility of the reaction, with the addition of primary and secondary alcohols to alkynes being relatively well-known, even at mild temperatures. Reports of the addition of tertiary alcohols and phenols are much rarer, and usually involve harsher conditions. Furthermore, simple gold phenolates which could potentially be formed in the reactions have been reported to be unstable, potentially leading to catalyst decomposition. ${ }^{31}$ An added problem when dealing with internal alkynes is the regioselectivity of the reaction. Alcohol additions to terminal alkynes generally occur at the internal carbon to give ketals or enol ether products, but internal alkynes usually give mixtures of regioisomers, especially when the two substituents have similar electronic properties. With intramolecular reactions the regioselectivity of the reaction can usually be controlled, as the kinetically faster ring formation will usually determine the selectivity.

\section{Scheme 1. Alkoxylation of Alkynes}

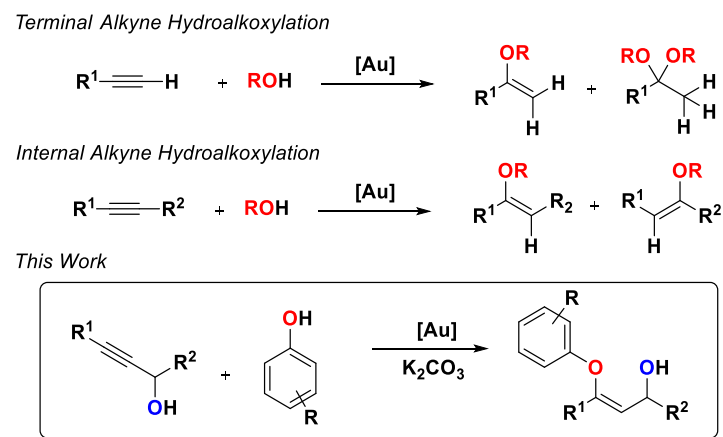

Propargylic alcohols are very versatile and readily available starting materials, where the presence of the alcohol group adjacent to the alkyne gives a distinctive reactivity which differs significantly from simple internal alkynes. Numerous methods to access useful building blocks from propargylic alcohols have been described in the literature. Our group and others have reported the gold-catalyzed transformation of propargylic alcohols into enones, ${ }^{32}$ bromo/fluoro enones, ${ }^{33,34}$ heterocycles ${ }^{35,36}$ or geminal dihalides. ${ }^{37}$ Recently we described how propargylic alcohols activated by the Gagosz catalyst ${ }^{38}$ could undergo regioselective hydroamination with anilines 
under mild conditions. ${ }^{39}$ We demonstrated that the $\mathrm{OH}$ played a key role in significantly increasing the reactivity of the triple bond, and directing the attack of the aniline regioselectively to form the 3-hydroxyimine.

Inspired by these results, we decided to explore the hydrophenoxylation of propargylic alcohols, with a view to improving the regioselectivity of previously reported alcohol additions to internal alkynes. Hydrophenoxylation of alkynes has seldom been reported, ${ }^{28-30}$ and although gold catalysts can mediate the reaction, harsh conditions are usually required and the reactions typically lack selectivity. We hereby report a method for the hydrophenoxylation of propargylic alcohols to yield phenyl enol ethers with high chemo- and regio- selectivity under mild conditions. The robustness of the reaction is demonstrated by a broad substrate scope both in terms of phenols and propargylic alcohols. The reaction can also be extended to Boc-protected propargylic amine substrates.

Table 1. Optimization of the Reaction Conditions

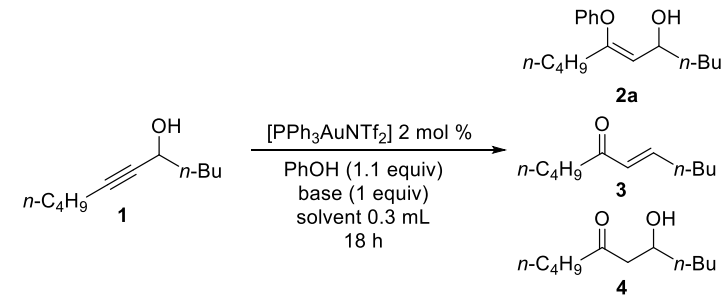

$\begin{array}{cccccc}\text { entry } & \text { base } & \text { solv. } & \begin{array}{c}\text { temp. } \\ \left({ }^{\circ} \mathrm{C}\right)\end{array} & \text { conv. } & \text { sel. (2a:3:4) } \\ \mathbf{1} & -- & \mathrm{CHCl}_{3} & \mathrm{rt} & 40 & 5: 70: 25 \\ \mathbf{3} & \mathrm{Cs}_{2} \mathrm{CO}_{3} & \mathrm{CHCl}_{3} & \mathrm{rt} & 0 & -- \\ \mathbf{4} & \mathrm{NaOAc}_{2} \mathrm{CHCl}_{3} & \mathrm{rt} & 58 & 67: 32: 1 \\ \mathbf{5} & \mathrm{K}_{2} \mathrm{CO}_{3} & \mathrm{CHCl}_{3} & \mathrm{rt} & 27 & 98: 1: 1 \\ \mathbf{6} & \mathrm{K}_{2} \mathrm{CO}_{3} & \mathrm{CHCl}_{3} & 50 & 99 & 98: 1: 1 \\ \mathbf{7} & \mathrm{Na}_{2} \mathrm{CO}_{3} & \mathrm{CHCl}_{3} & 50 & 82 & 98: 1: 1 \\ \mathbf{8} & \mathrm{K}_{2} \mathrm{CO}_{3} & \mathrm{PhMe}_{\mathbf{1 0}} & 50 & 72 & 98: 1: 1 \\ \mathbf{1 0} & \mathrm{K}_{2} \mathrm{CO}_{3} & \mathrm{PhCF}_{3} & 50 & 85 & 98: 1: 1 \\ & \mathrm{~K}_{2} \mathrm{CO}_{3} & \mathrm{C}_{6} \mathrm{H}_{5} \mathrm{~F} & 50 & 78 & 98: 1: 1\end{array}$

To investigate this reaction we chose the propargylic alcohol $\mathbf{1}$, derived from the addition of 1-hexyne to valeraldehyde. In our previous work, we have observed that addition of 4nitrophenol to the reaction of a propargylic alcohol with a gold catalyst promotes the formation of 3-hydroxyketone over Meyer-Schuster rearrangement to the enone. ${ }^{40}$ However, little or no addition of the phenol to the alkyne was observed in these reactions. Our first attempts at phenol addition in this study were not successful, and mixing phenol, 1 and gold catalyst in chloroform at room temperature gave only trace amounts of the addition product $\mathbf{2 a}$, together with the corre- sponding enone $\mathbf{3}$ and 3-hydroxyketone $\mathbf{4}$ after 18 hours. Previously reported phenoxylation reactions of alkynes have employed a stoichiometric amount of base $\mathrm{s}^{28-29}$ to partially deprotonate the phenol and increase its nucleophilicity. To our delight, upon the addition of sodium acetate the selectivity of the reaction towards the addition product $\mathbf{2 a}$ increased significantly (Table 1 , entry 3 ). Sodium acetate proved to lead to non-selective reactions, producing significant amounts of enone side-product 3. Optimization of the base and reaction parameters led us to identify $\mathrm{K}_{2} \mathrm{CO}_{3}$ and $50{ }^{\circ} \mathrm{C}$ as the ideal conditions. The optimization was carried out in $\mathrm{CHCl}_{3}$ but alternative non-chlorinated solvents can also be used including toluene, fluorobenzene or trifluorotoluene. We also examined a range of gold catalysts to explore the effect of ligands and counteranions $^{41}$ on the reaction. Comparable results were obtained with different non-coordinating counterions, and remarkably the reaction even proceeded effectively with a chloride counterion although the isolated yield of product was lower. A range of phosphine ligands were similarly effective in the reaction, whilst a gold complex bearing an NHC ligand was slightly less reactive. (See supporting information). As $\mathrm{PPh}_{3} \mathrm{AuNTf}_{2}$ is available commercially and gave the highest isolated yield of product, this was used in further reactions. The phenyl enol ethers were formed exclusively as the $Z$-isomer (NOE data for compound 2c, see supporting information), confirming that the gold catalyst promotes trans addition of the phenol across the alkyne.

Scheme 2. Enol Ether Scope with Phenols

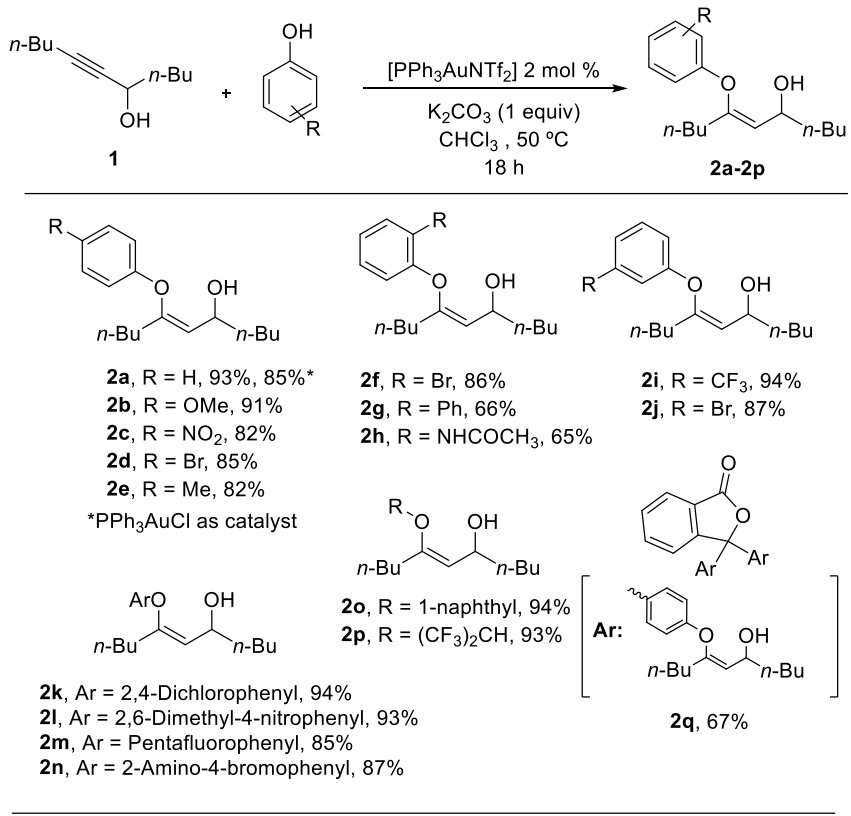

Once optimal conditions were identified, we set out to determine the scope of the reaction. First we focused on screening phenols using substrate $\mathbf{1}$ as the propargylic alcohol (Scheme 2 ). We examined the compatibility of the reaction with functionalized phenols and found that it tolerated a wide range of substituents on the phenol including electron-donating (Me, $\left.\mathrm{NH}_{2}, \mathrm{OMe}\right)$ or electron-withdrawing $\left(\mathrm{NO}_{2}, \mathrm{CF}_{3}, \mathrm{~F}, \mathrm{Cl}, \mathrm{Br}\right.$ and $\mathrm{Ph})$ groups. The reaction doesn't seem to be significantly affected by sterics as it proceeded smoothly with hindered phenols containing $\mathrm{Cl}$ or $\mathrm{Me}$ at the ortho positions $(\mathbf{2 f}, \mathbf{2 g}, \mathbf{2 h}$ 
and $\mathbf{2 k}$ ), and even when both ortho positions are substituted (2l). To our surprise, under the reaction conditions a phenol reacts preferentially to an adjacent aniline (2n) which we have shown can attack propargylic alcohols under similar reaction conditions in the absence of base. ${ }^{39}$ This result illustrates the higher reactivity of deprotonated phenols, and supports previous proposals that the gold catalyst can have a dual role in alkyne phenoxylations, activating both the alkyne and the phenol. ${ }^{29,30}$ Gold phenolates are reported in the literature ${ }^{31}$ and have been proposed as the nucleophilic species which attacks the electrophilic gold-alkyne complex. ${ }^{29}$ Hexafluoroisopropanol, which has a comparable acidity to phenol, can also undergo the reaction (2p), but typical alcohols $(\mathrm{MeOH}$, etc) were unreactive, even with the addition of stronger bases such as tert-butoxides or hydrides.

After determining the tolerance of the reaction conditions to a broad range of phenols, a variety of propargylic alcohols were examined. As can be observed in Scheme 3 a broad range of propargylic alcohols can be transformed into the corresponding phenyl enol ethers. Primary (8a), secondary (5a, 14a, 18a, 19a, 21a and 22a) and tertiary (6a, 7a, 12a, 16a and 23a) propargylic alcohols can be employed, including benzylic (9a, 10a, 11a, 13a, 15a, 17a and 20a) alcohols, and all smoothly undergo the addition reaction in high yield and with excellent selectivity. Aromatic rings on the alcohol can include electronwithdrawing groups (10a, 15a, 17a, 27a or 28a) or electrondonating groups (11a). Again the reaction shows tolerance of steric hindrance with substrates bearing cyclic alkylic chains (6a, 16a and 17a), isopropyl (18a) or tert butyl groups (26a) all giving good yields. Other functional groups such as diethyl acetals (12a, 14a) furan rings (20a), trifluoromethyl groups (23a) or alkenes (17a, 24a and 25a) are also well tolerated.

Double addition reactions are also possible using this methodology. Molecules with two phenols, such as phenolphthalein (Scheme 2, 2q) react with two equivalents of propargylic alcohol forming the double addition product in moderate yield. Double addition reactions can also be achieved in molecules with two alkyne moieties, including two different alkynes linked to the same alcohol group (Scheme 3, 29a), and a molecule containing two identical propargylic alcohol moieties (30a). These systems open up the possibility of forming molecules containing multiple enol ethers which could be of interest in coatings applications, where polyvinyl ethers are important starting materials.

Following the successful phenoxylation of propargylic alcohols, we decided to explore the reaction with analogous propargylic amines, which could also have the potential to undergo regioselective additions guided by hydrogen bonding. ${ }^{42}$ As alkylic amines are known to bond strongly to gold centers and prevent alkyne activation, we examined propargylic amines bearing electron-withdrawing groups to reduce nitrogen nucleophilicity. Sulfonamides proved to be unreactive and underwent deprotonation in the presence of $\mathrm{K}_{2} \mathrm{CO}_{3}$ and did not react further. Gratifyingly we found that a range of Bocprotected propargylic amines ${ }^{43}$ underwent the phenol addition reaction with complete selectivity and in moderate to good yields (Scheme 4).
Scheme 3. Scope with Respect to the Propargylic Alcohols

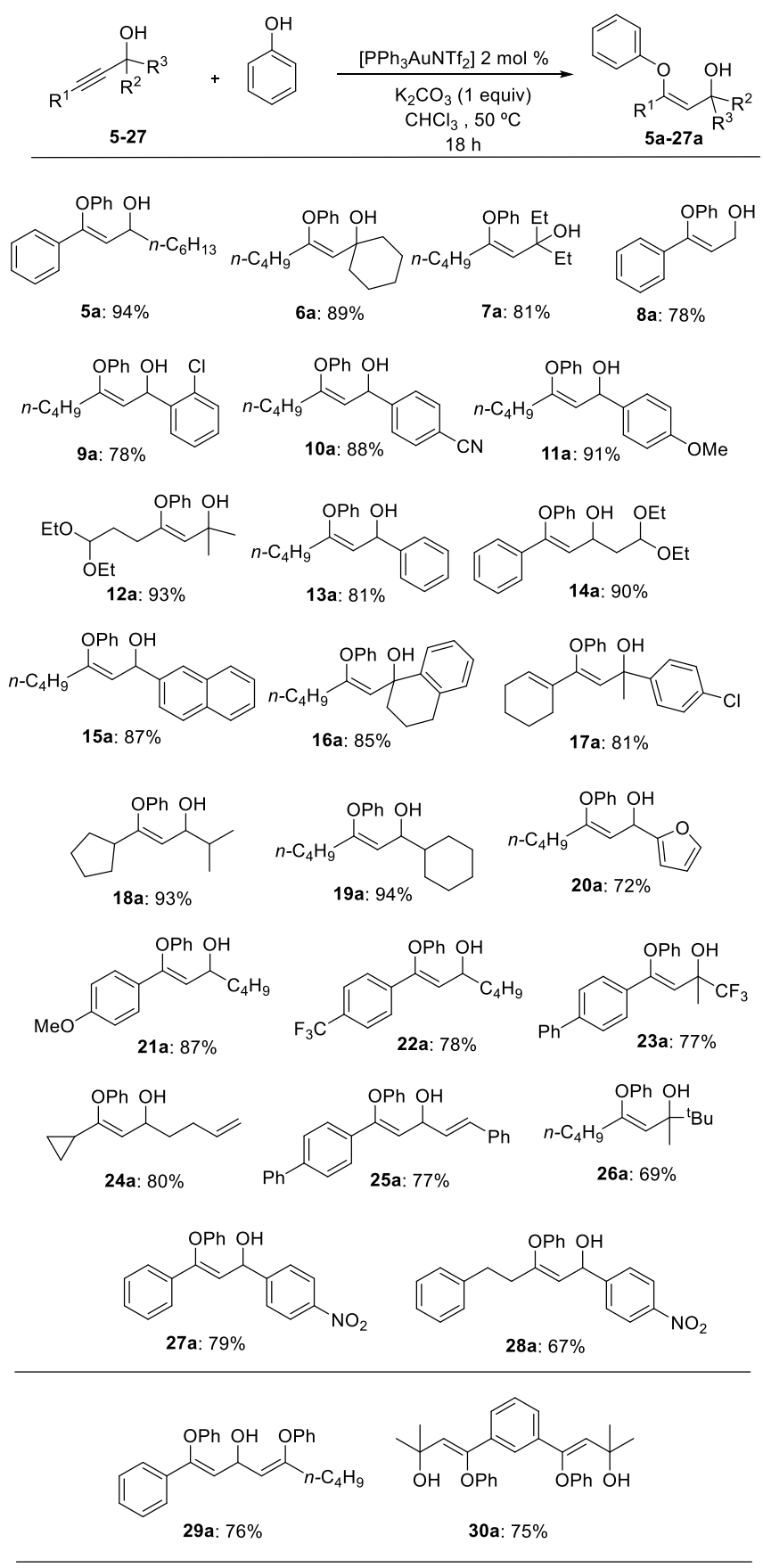


Scheme 4. Hydrophenoxylation of Propargylic Amines
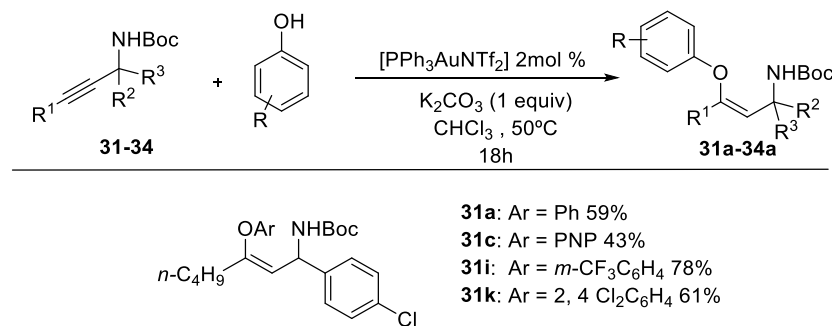

a: $\mathrm{Ar}=\mathrm{Ph} 59 \%$

31c: $\mathrm{Ar}=\mathrm{PNP} 43 \%$

31i: $\mathrm{Ar}=m-\mathrm{CF}_{3} \mathrm{C}_{6} \mathrm{H}_{4} 78 \%$

31k: $\mathrm{Ar}=2,4 \mathrm{Cl}_{2} \mathrm{C}_{6} \mathrm{H}_{4} 61 \%$
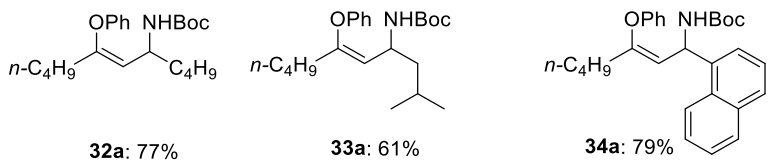

In conclusion we report a chemo- stereo- and regioselective method for the hydrophenoxylation of propargylic alcohols/amines to yield phenyl enol ethers in high yields. The method is very robust, tolerating a significant range of electronically/sterically diverse phenols, as well as propargylic alcohols and propargylic amines with a wide array of substitution patterns and functionalities. This is the first report describing the hydrophenoxylation of propargylic alcohols and propargylic amines, and further supports the role of adjacent hydrogen bonding groups in increasing the reactivity of alkynes towards gold-catalysed addition of nucleophiles in a stereoselective and regioselective fashion.

\section{ASSOCIATED CONTENT}

\section{Supporting Information}

The Supporting Information is available free of charge on the ACS Publications website.

\section{AUTHOR INFORMATION}

\section{Corresponding Author}

* Department of Chemistry, University College of London, 20 Gordon St, London, WC1H 0AJ (UK), tom.sheppard@ucl.ac.uk

\section{ACKNOWLEDGMENT}

We would like to thank the Leverhulme Trust for providing a grant (RPG-2017-221) to support this work.

\section{REFERENCES}

(1) Song, G.; Wang, F.; Li, X. C $-\mathrm{C}, \mathrm{C}-\mathrm{O}$ and $\mathrm{C}-\mathrm{N}$ Bond Formation via Rhodium (III)-Catalyzed Oxidative C-H Activation. Chem. Soc. Rev. 2012, 41, 3651-3678.

(2) Hartwig, J. F. Transition Metal Catalyzed Synthesis of Arylamines and Aryl Ethers from Aryl Halides and Triflates: Scope and Mechanism. Angew. Chem. Int. Ed. 1998, 37, 20462067.

(3) Monnier, F.; Taillefer, M. Catalytic C-C , C-N , and C-O Ullmann-Type Coupling Reactions. Angew. Chem. Int. Ed. 2009, 48, 6954-6971

(4) Enthaler, S.; Company, A. Palladium-Catalysed Hydroxylation and Alkoxylation. Chem. Soc. Rev. 2011, 40, 4912-4924.

(5) Patil, N. T.; Kavthe, R. D.; Shinde, V. S. Transition MetalCatalyzed Addition of $\mathrm{C}-$, $\mathrm{N}$ - and O-Nucleophiles to Unactivated C-C Multiple Bonds. Tetrahedron, 2012, 68, 8079-
(9)

8146

Goodwin, J. A.; Aponick, A. Regioselectivity in the AuCatalyzed Hydration and Hydroalkoxylation of Alkynes. Chem. Commun 2015, 51, 8730-8741

Scully, S. S.; Zheng, S.-L.; Wagner, B. K.; Schreiber, S. L. Synthesis of Oxazocenones via Gold (I)-Catalyzed 8-Endo-Dig Hydroalkoxylation of Alkynamides Org. Lett. 2015, 17, 418-421.

Hashmi, A. S. K.; Bührle, M.; Wolfle, M.; Rudolph, M.; Wieteck, M.; Rominger, F.; Frey, W. Gold Catalysis : Tandem Reactions of Diyne-Diols and External Nucleophiles as an Easy Access to Tricyclic Cage-like Structures. Chem. Eur. J. 2010 16, 9846-9854.

Barluenga, J.; Fernández, A.; Dieguez, A.; Rodríguez, F.; Fañanas, F. J. Gold- or Platinum-Catalyzed Cascade Processes of Alkynol Derivatives Involving Hydroalkoxylation Reactions Followed by Prins-Type Cyclizations. Chem. Eur. J. 2009, 15, 11660-11667.

(10) Hashmi, A. S. K.; Schwarz L.; Ji-Hyun Choi, J.-H.; Frost, T. M. A New Gold-Catalyzed $\mathrm{C}-\mathrm{C}$ Bond Formation. Angew. Chem. Int. Ed. 2000, 39, 2285-2288.

(11) Fukuda, Y.; Utimoto, K. Effective Transformation of Unactivated Alkynes into Ketones or Acetals by means of $\mathrm{Au}(\mathrm{III})$ Catalyst. J. Org. Chem. 1991, 56, 3729-3731.

(12) Santos, L. L.; Ruiz, V. R.; Sabater, M. J.; Corma, A. Regioselective Transformation of Alkynes into Cyclic Acetals and Thioacetals with a Gold (I) Catalyst: Comparison with Brønsted Acid Catalysts. Tetrahedron 2008, 64, 7902-7909.

(13) Corma, A.; Ruiz, V. R.; Leyva-perez, A.; Sabater, M. J. Regioand Stereoselective Intermolecular Hydroalkoxylation of Alkynes Catalysed by Cationic Gold (I) Complexes. Adv. Synth. Catal. 2010, 352, 1701-1710.

(14) Fukuda, Y.; Utimoto, K. Efficient Transformation of Methyl Propargyl Ethers into $\alpha, \beta$-Unsaturated Ketones. Bull. Chem. Soc. Jpn. 1991, 64, 2013-2015.

(15) Huang, L.; Arndt, M.; Heydt, H.; Gooßen, L. J. Late Transition Metal-Catalyzed Hydroamination and Hydroamidation. Chem. Rev. 2015, 115, 2596-2697.

(16) Teles, J. H.; Brode, S.; Chabanas, M. Cationic Gold(I) Complexes: Highly Efficient Catalysts for the Addition of Alcohols to Alkynes. Angew. Chem. Int. Ed. 1998, 37, 14151418.

(17) Pouy, M. J.; Delp, S. A.; Uddin, J.; Ramdeen, V. M.; Cochrane, N. A.; Fortman, G. C.; Gunnoe, T. B.; Cundari, T. R.; Sabat, M.; Myers, W. H. Intramolecular Hydroalkoxylation and Hydroamination of Alkynes Catalyzed by $\mathrm{Cu}(\mathrm{I})$ Complexes Supported by $\mathrm{N}$-Heterocyclic Carbene Ligands. ACS Catal. 2012, 2, 2182-2193.

Kondo, M.; Kochi, T.; Kakiuchi, F. Rhodium-Catalyzed AntiMarkovnikov Intermolecular Hydroalkoxylation of Terminal Acetylenes. J. Am. Chem. Soc. 2011, 133, 32-34.

(19) Varela-Ferna, A.; Gonza, C.; Castedo, L.; Saa, C. Cycloisomerization of Aromatic Homo- and BisHomopropargylic Alcohols via Catalytic Ru Vinylidenes: Formation of Benzofurans and Isochromenes. Org. Lett. 2007, $11,5350-5353$.

(20) Li, X.; Chianese, A. R.; Vogel, T.; Crabtree, R. H Intramolecular Alkyne Hydroalkoxylation and Hydroamination Catalyzed by Iridium Hydrides. Org. Lett. 2005, 7, 5437-5440. Dieguez-Vazquez, A.; Tzschucke, C. C.; Lam, W. Y.; Ley, S. V. $\mathrm{PtCl}_{4}$-Catalyzed Domino Synthesis of Fused Bicyclic Acetals. Angew. Chem. Int. Ed. 2008, 47, 209-212.

(22) Veenboer, R. M. P.; Dupuy, S.; Nolan, S. P. Stereoselective Gold(I)-Catalyzed Intermolecular Hydroalkoxlation of Alkynes. ACS Catal. 2015, 5, 1330-1334.

(23) Brenzovich, W. E. Gold in Total Synthesis: Alkynes as Carbonyl Surrogates. Angew. Chem. Int. Ed. 2012, 51, 89338935.

(24) Belting, V.; Krause, N. Gold-Catalyzed Tandem Cycloisomerization-Hydroalkoxylation of Homopropargylic Alcohols. Org. Lett. 2006, 8, 4489-4492.

(25) Reddy, M. S.; Kumar, Y. K.; Thirupathi, N. A New Synthesis of $\gamma$-Butyrolactones via $\mathrm{AuCl}_{3}$ or $\mathrm{Hg}$ (II) -Catalyzed Intramolecular Hydroalkoxylation of 4-Bromo-3-yn-1-ols. Org. Lett. 2012, 3, 11680-11683. 
Dieguez-Vazquez, A.; Tzschucke, C. C.; Crecente-campo, J.; Mcgrath, S.; Ley, S. V. $\mathrm{AuCl}_{3}$-Catalyzed Hydroalkoxylation of Conjugated Alkynoates: Synthesis of Five- and Six-Membered Cyclic Acetals. Eur. J. Org. Chem. 2009, 1698-1706.

(27) You, Z.; Hoveyda, A. H.; Snapper, M. L. Catalytic Enantioselective Silylation of Acyclic and Cyclic Triols: Application to Total Syntheses of Cleroindicins D, F, and C. Angew. Chem. Int. Ed. 2009, 48, 547-550.

(28) Kuram, M. R.; Bhanuchandra, M.; Sahoo, A. K. Gold-Catalyzed Intermolecular Hydrophenoxylation of Unactivated Internal Alkynes. J. Org. Chem. 2010, 75, 2247-2258.

(29) Oonishi, Y.; Gómez-suárez, A.; Martin, A. R.; Nolan, S. P. Hydrophenoxylation of Alkynes by Cooperative Gold Catalysis. Angew. Chem. Int. Ed. 2013, 52, 9767-9771.

(30) Gómez-suárez, A.; Oonishi, Y.; Martin, A. R.; Nolan, S. P. Scope and Limitations of the Dual-Gold-Catalysed Hydrophenoxylation of Alkynes. Beilstein J. Org. Chem. 2016, 12, 172-178.

(31) Ibrahim, N.; Vilhelmsen, M. H.; Pernpointner, M.; Rominger, F.; Hashmi, A. S. K.; Gold Phenolate Complexes: Synthesis, Structure, and Reactivity. Organometallics, 2013, 32, 25762583.

(32) Pennell, M. N.; Unthank, M. G.; Turner, P.; Sheppard, T. D. A General Procedure for the Synthesis of Enones via GoldCatalyzed Meyer-Schuster Rearrangement of Propargylic Alcohols at Room Temperature. J. Org. Chem. 2011, 76, 14761482.

(33) Ye, L.; Zhang, L. Practical Synthesis of Linear $\alpha$-Iodo/Bromo$\alpha, \beta$-Unsaturated Aldehydes/Ketones from Propargylic Alcohols via Au/Mo Bimetallic Catalysis. Org. Lett. 2009, 11, 36463649.

(34) Haro, T. De; Nevado, C. Domino Gold-Catalyzed Rearrangement and Fluorination of Propargyl Acetates. Chem. Commun. 2011, 47, 248-249.

(35) Cacchi, S.; Fabrizi, G.; Goggiamani, A.; Iazzetti, A. Construction of the 1,5-Benzodiazepine Skeleton from o-Phenylendiamine and Propargylic Alcohols via a Domino Gold-Catalyzed Hydroamination/Cyclization Process. Org. Lett.
2016, 18, 3511-3513

Kumar, Y. K.; Kumar, G. R.; Reddy, T. J.; Sridhar, B.; Reddy, M. S. Synthesis of 3-Sulfonylamino Quinolines from 1-(2Aminophenyl) Propargyl Alcohols through a Ag (I)-Catalyzed Hydroamination, $(2+3)$ Cycloaddition, and an Unusual StrainDriven Ring Expansion. Org. Lett. 2015, 17, 2226-2229.

(37) Oyley, J. M. D.; Aliev, A. E.; Sheppard, T. D. Regioselective Dihalohydration Reactions of Propargylic Alcohols: GoldCatalyzed and Noncatalyzed Reactions. Angew. Chem. Int. Ed. 2014, 53, 10747-10750.

(38) Ricard, L.; Gagosz, F. Phosphine Gold(I) Bis(Trifluoromethanesulfonyl) Imidate Complexes as New Highly Efficient and Air-Stable Catalysts for the Cycloisomerization of Enynes. Org. Lett. 2005, 7, 4133-4136.

(39) Laserna, V.; Sheppard, T. D. Gold Catalyzed Hydroamination of Propargylic Alcohols: Controlling Divergent Reaction Pathways to Access 1,3-Aminoalcohols, 3-Hydroxyketones or 3Aminoketones. ChemRxiv. Prepr. 2018 , https://doi.org/10.26434/chemrxiv.7160639.v1.

(40) Pennell, M. N.; Kyle, M. P.; Gibson, S. M.; Male, L.; Turner, P. G.; Grainger, R. S.; Sheppard, T. D. Intercepting the GoldCatalysed Meyer-Schuster Rearrangement by Controlled Protodemetallation: A Regioselective Hydration of Propargylic Alcohols. Adv. Synth. Catal. 2016, 358, 1519-1525.

(41) Schieß1, J.; Schulmeister, J.; Doppiu, A.; Wörner, E.; Rudolph, M.; Karch, R.; Hashmi, A. S. K. An Industrial Perspective on Counter Anions in Gold Catalysis: On Alternative Counter Anions. Adv. Synth. Catal. 2018, 360, 3949-3959.

(42) Ying, J.; Wang, H.; Qi, X.; Jin-Bao Peng, J.-B.; Wu, X.-F. Gold-Catalyzed Regiospecific Hydration of $N$-Tosyl Propargylic Amines, Organometallics, 2018, 37, 2837-2841.

(43) Tiziana Mecozzi, T.; Petrini, M.; Synthesis of Allylic and Propargylic Primary Amines by Reaction of Organometallic Reagents with $\alpha$-Amidoalkyl Sulfones. J. Org. Chem. 1999, 64, 8970-8972. 